\title{
Immigrant optimism or immigrant pragmatism? Linguistic capital, orientation towards science and occupational expectations of adolescent immigrants
}

\author{
Joanna Sikora ${ }^{1 *}$ (ID and Artur Pokropek ${ }^{2}$
}

*Correspondence:

Joanna.Sikora@anu.edu.au

${ }^{1}$ Research School of Social

Sciences, Australian National

University, Canberra, ACT

2601, Australia

Full list of author information

is available at the end of the

article

\begin{abstract}
Background: Studies demonstrate that occupational optimism can boost adolescents' academic attainment and perseverance in education. To contribute to this literature, we consider two hypotheses. The first posits that bilingual immigrants are remarkably resourceful and determined. Thus, they are more occupationally ambitious than their peers. The second proposes that immigrant students engage in "strategic adaptation" by specializing in science, viewed as a level playing field.

Methods: To assess these hypotheses at two points of time, we analyze data from 19 societies that participated in the Programme for International Student Assessment (PISA) in 2006 and 2015. Our primary method is path analysis with balanced replicate weights (BRR) undertaken separately for each country's data.

Results: We find that, in many countries, bilingual immigrants expect to enter higher status occupations than non-immigrants. However, immigrants who do not speak another language are also optimistic, so linguistic resources cannot explain occupational ambition. Furthermore, immigrants accord science more instrumental value and enjoy it more at school, which accounts, across societies, for up to $12 \%$ of the variation in vocational optimism indicated by the expected occupational status, and up to $41 \%$ in plans to pursue a career in science professions.
\end{abstract}

Conclusion: Our results align with the "strategic adaptation" argument that many young immigrants might seek to specialize in science as a pragmatic tactic to ensure high occupational attainment.

Keywords: Immigrant adolescents, Linguistic capital, School science, Occupational expectations, PISA, Cross-national comparisons

\section{Introduction}

As children of immigrants make up a rapidly growing share of the youth population across the world (Suárez-Orozco 2018), factors that affect their motivation for educational and occupational attainment engender more interest (Alarcon et al. 2014; Feliciano and Lanuza 2016; Schleicher 2015; Wicht 2016). Of these, immigrant optimism,

(c) The Author(s) 2021. This article is licensed under a Creative Commons Attribution 4.0 International License, which permits use, sharing adaptation, distribution and reproduction in any medium or format, as long as you give appropriate credit to the original author(s) and the source, provide a link to the Creative Commons licence, and indicate if changes were made. The images or other third party material in this article are included in the article's Creative Commons licence, unless indicated otherwise in a credit line to the material. If material is not included in the article's Creative Commons licence and your intended use is not permitted by statutory regulation or exceeds the permitted use, you will need to obtain permission directly from the copyright holder. To view a copy of this licence, visit http://creativeco mmons.org/licenses/by/4.0/. 
operationalized as expectations of high-level educational and occupational attainment relative to family origins, has been systematically reported in the USA (Feliciano and Lanuza 2016; Kao and Tienda 1995; Portes and Rumbaut 2001) and other affluent societies (Khattab 2018; Medvedeva and Portes 2017; Tjaden and Hunkler 2017). Optimism varies by ethnic origins and host country contexts, and some immigrant youth are pessimistic about their future educational outcomes (Khattab 2018; Yiu 2013). Nevertheless, the academic optimism of immigrant youth, particularly the intention to study at university, has attracted the most attention (Cebolla-Boado and Martinez De Lizarrondo 2015; Gil-Hernández and Gracia 2018; Khattab 2018; Medvedeva and Portes 2017). In contrast, occupational expectations elicit less interest, even though both motivational variables are closely related and mutually reinforcing (Feliciano and Rumbaut 2005; Tseng 2006; Xie and Goyette 2003). As the numbers of university graduates grow, occupational goals become an arguably better gauge of optimism. While most professional jobs require a university degree, some offer higher status, more income and flexibility than others. The optimism of young immigrants has been attributed to parental ambition, peer or co-ethnic networks, socio-economic selectivity of immigrant groups and the economic, institutional and cultural contexts in host societies (Lee and Zhou 2015; Portes and MacLeod 1999; Yiu 2013). Furthermore, links have been found between optimism and bilingualism (Medvedeva and Portes 2017). We begin this paper by considering these links and conceptualizing them as linguistic capital (Yosso 2005).

Linguistic resources are also relevant to the "strategic adaptation" argument (Lee and Zhou 2015; Xie and Goyette 2003), which proposes that immigrants circumvent potential discrimination by seeking careers in science and technology, because of universalistic values that permeate these fields. As universalism ensures putting performance before personal characteristics, "discrimination is relatively easier to combat in technical occupations due to the availability of objective criteria for hiring and advancement" (Xie and Goyette 2003: 478).

The linguistic capital and the strategic adaptation hypotheses have not been evaluated in a comparative perspective. Most likely, the key reason for that is that single-country studies showed youth optimism to vary by ethnic origins as well as contexts in host societies. For instance, the Chinese youth in the USA tend to be ambitious, while their counterparts in Spain do not hope to do well in education (Yiu 2013). However, a comparative investigation of immigrant optimism does not have to stem from universalist assumptions that similar causes underpin similar outcomes for migrant youth across societies. Instead, comparative analyses can identify the extent to which particular patterns prevail, appearing to be underpinned by factors of "broader, collective scope" (Portes and MacLeod 1999: 390). Such contributions, where over-time trends are examined, can complement the existing and inspire future single-country longitudinal studies. Therefore, in this paper, we evaluate three sets of hypotheses about the occupational optimism of adolescent immigrants, their linguistic resources, and orientations towards science.

We focus on 19 OECD societies with sufficient counts of immigrant youth, where similar policy efforts attempted to address shortages of technical skills (OECD 2016a). Our data come from the 2015 Program for International Students Achievement, and we replicate our analyses in the 2006 PISA data to assess the sensitivity of our results to time and cohort variation. 
Prior research (Kao and Tienda 1995) found that many linguistically diverse immigrant grow up in families strongly oriented towards educational and occupational achievement. Therefore, we expect bilingual immigrants to be more occupationally ambitious than their otherwise comparable peers. Studies also indicate that many immigrant parents and their children construe science and technology as level playing fields that promise greater ease of geographic mobility and skill transferability (Lee and Zhou 2015). Consequently, immigrant youth are hypothesized to display a more instrumental orientation towards science (Xie and Goyette 2003). Moreover, due to universalistic principles that underpin science, immigrant students are expected to enjoy it more at school. As a result, at the group level, these positive attitudes to science, which may reflect a pragmatic adaptation strategy, ought to explain some vocational optimism among adolescent immigrants.

\section{Theory and prior research Immigrant optimism}

The most influential accounts of occupational and educational optimism among young immigrants have so far originated in the United States (Feliciano and Rumbaut 2005; Kao and Tienda 1995; Portes and Rumbaut 2014). Optimism manifests itself in highly ambitious educational (Kao and Tienda 1995) and occupational expectations (Davis 2013; Feliciano and Rumbaut 2005) evident among immigrants in secondary education once disparities in the family socio-economic background between them and nonimmigrants are factored in. Optimism is relative to immigrants' starting points, which denote attainment in their family of origin, co-ethnics, pan-ethnics, or other reference groups. Expectations often become a self-fulfilling prophecy when ambitious youth attain high educational qualifications and occupational ranks (Feliciano and Rumbaut 2005; Khattab 2018; Portes and Rumbaut 2014). Attainments of some immigrant youth exceed what could be typically expected (but see: Tjaden and Hunkler 2017 for an analysis of adverse outcomes attributable to immigrant optimism). Occasionally, immigrant optimism has been attributed to the hyper-selectivity of immigrant groups (CebollaBoado and Soysal 2018), when they are, on average, more educated than their host society peers and co-ethnics in their home country. Yet, optimism is known to persist also among disadvantaged youth who have limited access to economic or social resources (Lee and Zhou 2015). The term immigrant paradox denotes achievement fuelled by high attainment ambitions inconsistent with the modest backgrounds of many immigrant parents and co-ethnics (Lee and Zhou 2015). Parental success frames, which are culturally enforced expectations of what counts as noteworthy educational and occupational achievement, along with parental social and human capital are often identified as critical determinants of high expectations held by immigrant youth (Feliciano and Lanuza 2016; Kao and Tienda 1995; Portes and Rumbaut 2006). Immigrant optimism does not occur always and everywhere (Khattab 2018; Yiu 2013), but in the USA, Kao and Tienda (1995) argued that many immigrant children grew up in families strongly oriented towards academic achievement in which parents sustained high hopes for their offspring. Similarly, Feliciano and Lanuza (2016) identified linguistic capital and the high value placed on educational pursuits in many immigrant families as two crucial sources of immigrant advantage. 


\section{Linguistic capital: ambition among bilingual immigrants}

Linguistic capital, particularly fluent bilingualism, has been believed to foster optimism among immigrant adolescents (Medvedeva and Portes 2017; Portes and Rumbaut 2001). Extensions of Bourdieu's reproduction theory (Bourdieu and Passeron 1990), such as specific strands of critical race theory (Yosso 2005), construe bi- and multilingualism as cultural wealth. It comprises linguistic capital, namely, "the intellectual and social skills attained through communication experiences in more than one language and style" (Yosso 2005:79). This form of capital enables youth to hone cognitive skills that help develop resilience and resistance to the pressures to assimilate (Kasinitz et al. 2008). These qualities help persist in education, even when youth struggle to succeed (Khattab 2018; Ogbu 1978). This form of capital differs from multilingualism in societies with two or more official languages in that the minority language skills of immigrants are a source of identities that usually are not valued in the formal education system (Hakuta 2010). While not appreciated in the same manner as those possessing local language skills, non-monolingual minority youth develop considerable plasticity, flexibility and adaptability (Devine 2009).

Bilingualism coexists with family value systems that prioritize academic achievement because the work on maintaining two or more languages is itself an indication of ambition (Medvedeva and Portes 2017). Studies have also pointed out that bilingual students might cognitively benefit through better understanding meta-language, which facilitates some aspects of schoolwork in ways not accessible to non-immigrant youth (Clarkson 2007). This perspective suggests that immigrants who speak different languages at school and home form extra ambitious goals about their future. As occupational goals precede educational attainment objectives (Xie and Goyette 2003), this includes career plans to enter high-status professional employment.

In contrast to studies that draw a clear distinction between first, one-and-a-half and second-generation immigrants, Yosso's version of the critical race theory stipulates that the ambitions of linguistically diverse immigrants are alike across generations (2005). However, the traditional "accommodation without assimilation" argument pays more attention to the concept of generation. It expects recent arrivals, i.e. first-generation students, to be remarkably motivated to achieve (for a discussion, see Kao and Tienda 1995). Still, it poses that the second generation is most likely to attain their ambitious goals.

\section{Pragmatism: orientation towards science and technology as a strategic adaptation}

The strategic adaptation argument approaches language diversity from a different angle (Chiswick and Taengnoi 2007; Xie and Goyette 2003). It sees diversity as only one of several reasons why young immigrants orient themselves to specific careers. Drawing on the Wisconsin attainment model (Haller and Portes 1973) and Swidler's theory of cultural strategies (1986) it expects immigrants to be: "socialized to think that academic achievement is the surest way to upward mobility" (Xie and Goyette 2003: 473). Immigrants might lack language competencies, social capital or confidence to pursue careers in arts, government, or politics. Thus, they might turn to science and technology, which are reputed to operate following relatively universalist values. This universalism means that individual performance, judged by explicit criteria, is more relevant "than personal 
characteristics that are functionally irrelevant (such as race, religion and social origins)" (Xie and Goyette 2003: 476). Other research on immigrants in the USA also emphasizes that "Fields such as medicine, law, science, and engineering require exceptional educational achievement, credentials, and hard skills that may obviate or lessen the potential discrimination and bias." (Lee and Zhou 2015: 58) One immigrant mother summarised this belief by stating that "in math, there is always a right answer; one plus one always equals two. It's not that way in the arts" (Lee and Zhou 2015: 58). Thus, opting for careers in creative fields, including performance or visual arts or politics, might make immigrant children more dependent on subjective and potentially biased evaluations.

This argument is subject to at least two qualifications. First, it is not easy to empirically demonstrate that all immigrants engage in the considerations described above. Instead, in line with the literature on self-expression, in post-industrial societies, the dominant ideologies construe vocational choices in purely individualistic terms as acts of selfexpression that match personality traits (Inglehart and Welzel 2005). Thus, as their nonimmigrant peers, many immigrant youths are likely to perceive their career choices not as a strategic response to the constraints inbuilt in societal systems but rather as their self-expression. For instance, studies of persistent gender self-sorting that affects young people's field-of-study and career decisions have highlighted such reasoning (Charles and Bradley 2009; Sikora and Pokropek 2012a). Young people in post-industrial societies choose areas of study and careers in a strongly gender-stereotyped manner while viewing their decisions not as structurally conditioned but motivated by personal joy and satisfaction.

Second, immigrant attitudes to science could be more favourable (OECD 2016b), because of the perception that science occupations ensure more skill transferability and geographic mobility, which is potentially more attractive to immigrants (Boyd and Tian 2018). However, it is not clear how this would differ from cosmopolitan capital, which comprises skills to effectively navigate new and culturally challenging environments, also valued by non-immigrant sojourners (Weenink 2008). Thus, the value placed on skill transferability and geographic mobility is less compelling in explaining the differences in science orientations between immigrant and non-immigrant youth.

In sum, prior literature emphasizes the tendency of young immigrants to specialize in science to circumvent potential discrimination as well as neutralizing the lack of cultural competencies that facilitate entry into creative fields or politics. Immigrants are overrepresented amongst engineers and scientists in many countries (Han 2016; Min and Jang 2015), which can further reinforce the perception that science specialization is an appropriate career choice for a young immigrant. However, the dominant ideology of individualism construes career preferences as reflections of personal identities rather than structural conditions. Thus, it is worth while to consider students' perceptions of instrumental value and enjoyment attached to science as prerequisites for their occupational ambition and, more precisely, a plan to pursue a professional career in science.

\section{Relative versus absolute optimism: the importance of starting points and contexts}

Accounting for the differences in the socio-economic background is integral to the concept of immigrant optimism. Immigrant students lag behind their non-migrant peers in ambitions in achievement in some societies and surpass them elsewhere, 
particularly in communities with long histories of selective skilled immigration (Dustmann et al. 2012). Therefore, optimism might not be evident unless it is understood in relative terms, taking into account students' socio-economic status and their prior academic achievement (Xie and Goyette 2003). The latter, in many countries, leaves immigrants at a disadvantage but, elsewhere, immigrants outdo their peers in education (Entorf and Minoiu 2005; Hillmert 2013). Where science outcomes are concerned, it is also necessary to factor in parental employment in science to allow for the effects of within-family socialization (Sikora and Pokropek 2012b).

Moreover, to make meaningful international comparisons of occupational expectations, it is necessary to recognize that, across countries, students are directed into vocational streams at different stages of their educational careers (Dronkers et al. 2012; Tjaden and Hunkler 2017). The timing of this sorting matters because once students find themselves in vocational streams, they report occupational expectations of lower status than similar students just before this transition. All these factors make up starting points that demarcate vocational optimism.

Prior PISA-based studies of educational achievement and attitudes among adolescent immigrants often included country characteristics and attempted to explain between-school and between-country variation (e.g. Dronkers et al. 2012; Hillmert 2013). However, compositions of our migrant groups, as well as mechanisms that bring about either immigrant optimism or pessimism, are likely to vary across country contexts. Therefore, and due to our theories of individual motivation, we focus at this stage solely on student-level variables.

Hypotheses Prior literature cautions against blanket assumptions that the same reasons underpin immigrant motivation across different contexts. Therefore, we model immigrant ambition separately by country, leaving modelling of cross-country variation for future research. Our contribution to the literature on immigrant optimism involves evaluating, in each country, the three sets of hypotheses outlined in Fig. 1, in parts a, b and c. While our modelling strategy is designed to reveal variation, our theories suggest that these hypotheses will be supported in all countries.

In the first set, we consider whether immigrant optimism could stem from linguistic diversity (Fig. 1a), as proposed by Yosso's exposition of critical race theory (2005). We operationalize linguistic diversity as speaking at home a language different from the language of school instruction. Some families may speak a second language at home; others speak more than two languages. Moreover, some schools offer education in two or more languages. However, our data only allow us to categorize as non-monolingual the immigrants who report using at home a language that is different from the language of their PISA test. Other immigrants, i.e. those who use at home their language of the test, are treated as monolinguals. We ask if so-defined non-monolingual (henceforth bilingual) immigrants are significantly more ambitious than other students. Our first set of hypotheses are as follows:

Hypothesis 1a Bilingual migrants are significantly more ambitious than all other students. 
a Linguistica capital and adolescent occupational expectations

\section{Linguistic capital:}

Non-immigrants

Monolingual immigrants

Bi- and multi-lingual immigrants

\section{Expected occupational status (ISEI)}

b. Orientation to science and adolescent occupational expectations

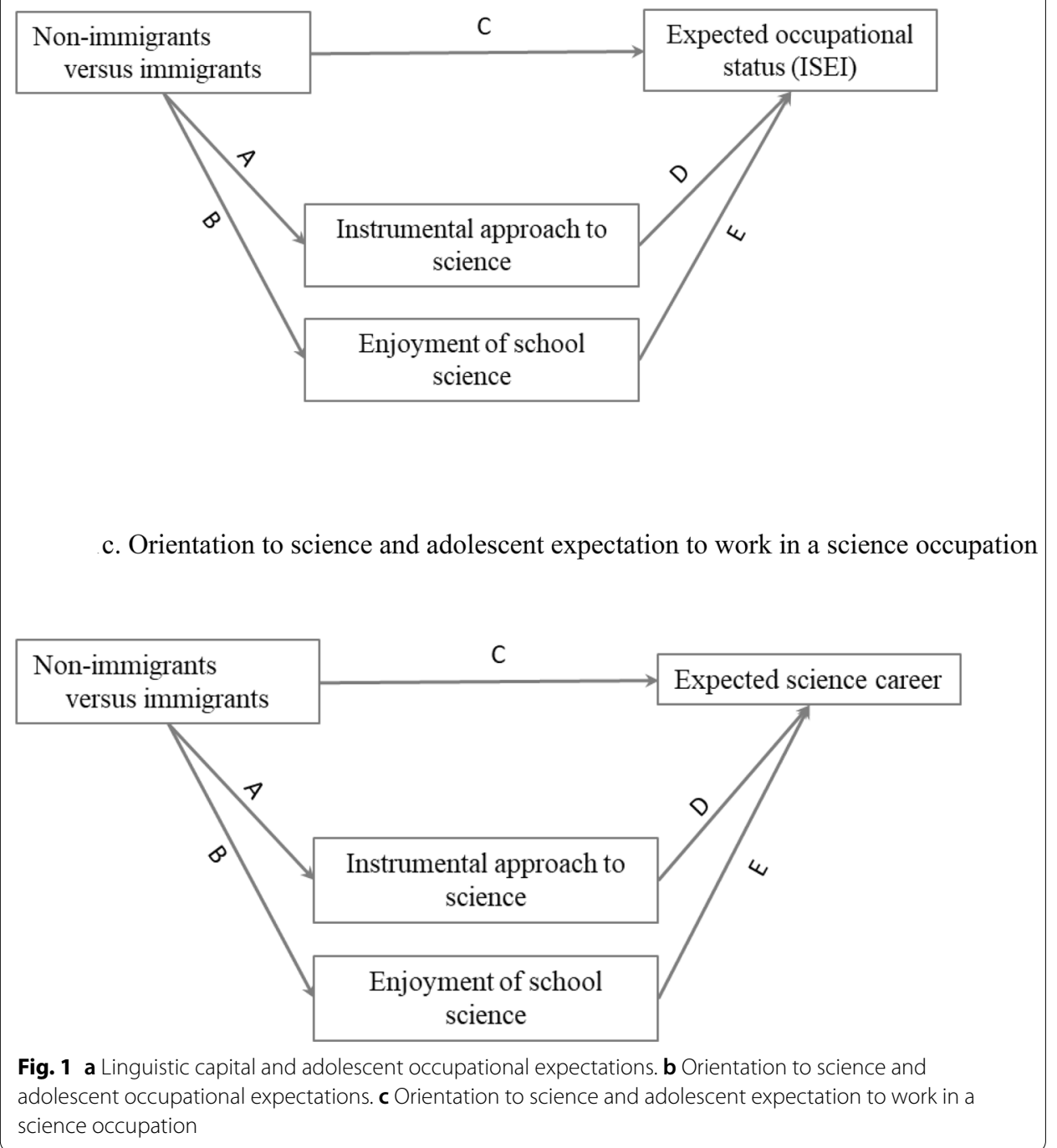

Hypothesis $1 b$ Immigrants, regardless of their linguistic background, are more ambitious than their peers. Moreover, bilingual migrants outstrip monolinguals by a discernible margin. 
We consider Hypothesis 1a or H1a to be a strong version of H1b, which is a weak version of the linguistic impact hypothesis.

The strategic adaptation literature informs the second set of hypotheses. They are as follows.

Hypothesis $2 a$ Immigrant youth are more inclined than comparable peers to view science as a valuable domain for securing future employment (Path A in Fig. 1b).

Hypothesis $2 b$ Immigrant students report enjoying science more than their peers (Path $B$ in Fig. 1b).

Hypothesis $2 c$ Instrumental motivation to study science (Path D in Fig. 1b) and enjoyment of science (Path E in Fig. 1b) explain part, but not all (Path C in Fig. 1b), of immigrant occupational optimism, indicated by expected high occupational status.

We expect immigrant students to report that they enjoy science more than their peers (H2b and Path B in Fig. 1b) due to the reputation of science as an equal playing field not only in occupational settings but also in education. The recognition that students are likely to construe vocational choices as individual self-expression also underpins this hypothesis.

Finally, given the focus of our theory on science employment, the third set of hypotheses explicitly concerns the expectation to become a science professional (Fig. 1c) as the modelled outcome.

Hypothesis 3 Instrumental motivation to study science (Path D in Fig. 1c) and enjoyment of science (Path E in Fig. 1c) explain part, but not all (Path C in Fig. 1c), of immigrant expectations to work as a scientist.

\section{Data, measures, and methods \\ Data}

We analyze the OECD's Program for International Student Assessment 2015 data (OECD 2017), and, as sensitivity analysis, we also replicate all models in PISA 2006 (OECD 2007) in supplementary materials. Sensitivity analysis reveals the extent to which variations in PISA sample migrant compositions that occurred in the decade between 2006 and 2015 might lead to substantively different conclusions. Not all countries had enough immigrants to make reliable estimations. Hence, we settled on nations with at least 10 per cent of immigrants in their samples, of whom at least $30 \%$ and no less than 30 spoke at home a language different from the language of the PISA test. We use the PISA definition of immigrants, i.e. respondents whose both parents were born in another country, although others classify students with one foreign-born parent as immigrants (Medvedeva and Portes 2017). Analyses using the latter definition, available upon request, were also undertaken and corresponded to the results presented here. These selection steps left us with 19 OECD countries, who participated in both PISA surveys. They are Australia, Austria, Belgium, Canada, Germany, Denmark, France, 
Greece, Great Britain, Ireland, Israel, Luxembourg, Netherlands, Norway, New Zealand, Spain, Sweden, Switzerland, and the United States.

\section{Measures}

Dependent variables

Immigrant optimism: occupational expectation in ISEI scores A single question was used to derive our first dependent variable.

What kind of job do you expect to have when you are about 30 years old? Write the job title:

The answers were initially coded into the International Standard Classification of Occupation ISCO-08 codes (ILO 2012), and later into the International Socio-Economic Index for occupational status (ISEI) (Ganzeboom and Treiman 2010; Ganzeboom et al. 1992). This index ranges from a low of 16 to a high of 90, where the lowest scores denote unskilled occupations such as farmhands and fruit pickers, and the highest scores signify skilled professional careers such as surgeons, or judges in courts of law.

\section{Expectation to work in a science profession}

We supplement models of vocational optimism in ISEI scores with modelling students' plans to enter a career in science. For this purpose, we use a dummy variable created from the ISCO codes through a previously used coding scheme (OECD 2016b see p. 283 Table A1.1) and (Sikora and Pokropek 2012a). Science encompasses not only mathematics, engineering and computing but also medicine and health professions. Codes that relate to medicine, life science, engineering, computing, mathematics, physics (ISCO08 groups 21,22, 25, 311, 314, 315 and 32 plus 2634, 1311,1312, 1330, 1342, 1343 but excluding 2163, 2166, 323, 3252, 3258, 3510 and 3520) were treated as science while other occupations were not. This variable is a high-quality indicator, as students had to nominate a verbatim job, rather than vaguely indicating on an attitudinal scale how strong their interest in future science work was.

\section{The instrumental value of science}

Our argument hinges on the assumption that immigrants accord more instrumental value to science so, in the second stage of analyses, we use the OECD index comprising four statements with a four-point Likert scale of agreement (for details of scale construction and measurement properties see p. 315 in OECD 2017) a) 'Making an effort in my school science is worth it because this will help me in the work I want to do, later on, b) What I learn in my school science is important for me because I need this for what I want to do, later on, c) Studying my school science is worthwhile for me because what I learn will improve my career prospects and d) Many things I learn in my school science will help me to get a job. This scale is expressed in standard deviations.

\section{Enjoyment of science}

Another OECD index gauges the joy of science (OECD 2017 see pp. 311-312). It comprises the following items: 'How much do you agree with the statements below? a) I generally have fun when I am learning science topics. b) I like reading about science c) I am 
happy doing science problems, d) I enjoy acquiring new science knowledge e) I am interested in learning about science. Answer categories were 'strongly agree,' 'agree', 'disagree' and 'strongly disagree.' This scale has also been standardized across OECD countries (OECD 2017).

\section{Independent variables}

Our control variables include students' gender and parents' economic and socio-economic status (ESCS). ESCS, created by the OECD, is a comprehensive measure informed by Bourdieu's conception of social class (1984). It combines the International SocioEconomic Index of Occupational Status (ISEI), which depicts parental occupation and parental education converted into years of schooling. Moreover, it includes the PISA indices of family wealth; home educational possessions; and high-brow culture in the family home (OECD 2007, p. 346). To control for parental employment in science, we use a dummy variable where zero denotes neither parent working in science, 1 represents one parent, and 2 indicates that both parents are scientists. To manage the layout of our large tables, we use this trichotomy as a continuous variable. The results with dummy variables are equivalent and available upon request. Science employment is defined using the same ISCO codes as students' occupational expectations. We also use the ten plausible values for science test scores available in PISA 2015 as a proxy for prior academic achievement. The scale had a mean of 500 and a standard deviation of 100 for the OECD nations (OECD 2017). To reduce the number of reported decimals, we have rescaled it to a mean of 5 and a standard deviation of 1 . Finally, we control for students' placement in vocational streams. This control is crucial for comparability as students participate in PISA just before or just after the sorting into academic and vocational streams, which is known to affect occupational plans. For comparison, all models without this variable have been provided in Additional file 1: Appendix S3. They lead to the same conclusions.

\section{Method}

We performed analyses in Fig. 1a, using Stata 15 and linear regressions with balanced repeated replicate (BRR) weights (Avvisati and Keslair 2017). The weights correct for PISA's two-stage sampling design, which involves first sampling schools and then students (OECD 2017). Models in Fig. $1 \mathrm{~b}$ and c are path analyses, estimated also in Stata 15 , in the structural equations modelling framework with BRR weights, ensuring that standard errors for indirect effects are correct. The ISEI scores and then the plan to work as a science professional are outcome variables. The instrumental approach to science and enjoyment of science are simultaneously the mediating and the outcome variables. Because PISA relies on ten plausible values to indicate students' achievement, we used chained imputations to generate ten datasets with imputed missing values separately in each of 19 countries and estimated all models by combining the estimates by using the Rubin rule (Little and Rubin 2002; OECD 2017). Analyses of missing data for occupational variables in PISA 2015 show this is the optimal approach (Blasko et al. 2018). We also estimated all models with listwise deletion, which led to equivalent results. The estimates reported here are on the imputed data leading to less bias (Newman 2014; Schafer and Graham 2002). To model expectations of science careers, a binary variable, we used 
linear probability models for consistency and ease of interpretation. However, the results of logistic regressions are equivalent and available upon request.

\section{Data limitations}

Initially, we considered the differences between students with different linguistic capitals within immigrant generations, i.e. the first generation, one-and-a-half and the second generation (Rumbaut 2012) using the PISA and Portes-and-Rumbaut (2001) definitions. The former treats students with only one foreign parent as a non-migrant, the latter as a migrant. However, preliminary analyses showed that the results do not vary by generation, possibly due to small numbers in language-by-generation categories. Therefore, we do not report generational differences. The PISA data are cross-sectional rather than longitudinal. They do not provide as much detail on immigrant life trajectories as special-purpose migrant panel surveys. However, they are a unique source of comparable information about teenage immigrants in multiple host countries that can serve as a springboard to discuss motivation processes likely to occur in different host society contexts.

\section{Results}

The first glance at the unadjusted average expected occupational status of students suggests that immigrant optimism exists only in some countries and varies considerably by linguistic resources.

In Australia, Canada, Denmark, Great Britain, Ireland, Netherlands, New Zealand, Sweden and the United States, immigrants in both language groups are more ambitious than their native peers, with the differences by language negligible rather than large (Table 1). By contrast, in Belgium, Germany, Greece, Israel, Spain and Switzerland, immigrants are no more optimistic than their non-immigrant counterparts. Finally, in Austria, France and Luxembourg, only immigrants, who speak the same language at home and school, hope for higher status jobs than their non-migrant peers. Only in Norway do linguistically diverse immigrants show more optimism than either of the comparison groups.

\section{Multivariate analyses}

In line with the arguments that call for conceptualizing migrant optimism in relative rather than absolute terms, the picture changes when some key starting points, i.e., students' socio-economic background, prior academic achievement, placement in a vocational program and gender, are accounted for (Table 2). Immigrant optimism occurs in many places but not everywhere. Students in Greece and Israel do not differ in their occupational ambitions regardless of their linguistic competencies or migrant status. Elsewhere, however, migrants are more occupationally optimistic.

\section{Immigrant optimism — relative to family background and school performance-exists in many} places

In 17 countries, immigrant students expect to enter higher status jobs, with the advantage of between 2.1 points for monolingual immigrants in Luxembourg and 15.8 points for bilinguals in Sweden on the ISEI scale ranging from 16 to 90 (Table 2). However, 
Table 1 Occupational expectations of non-immigrants and immigrants with differing linguistic capitals: average ISEl occupational status scores ranging from 16 to 90

\begin{tabular}{|c|c|c|c|c|c|c|c|c|c|}
\hline & Non-migrants & S.E & $\mathrm{N}$ & $\begin{array}{l}\text { Migrants speak } \\
\text { different language } \\
\text { home \& school }\end{array}$ & S.E & $\mathrm{N}$ & $\begin{array}{l}\text { Migrants speak } \\
\text { same language } \\
\text { home \& school }\end{array}$ & S.E & $\mathrm{N}$ \\
\hline Australia & 61.7 & 0.27 & 11,590 & 70.1 & 0.74 & 1144 & 68.1 & 0.53 & 1796 \\
\hline Austria & 59.5 & 0.60 & 5669 & 61.2 & 1.12 & 988 & 65.2 & 1.46 & 350 \\
\hline Belgium & 61.0 & 1.01 & 3129 & 64.7 & 1.58 & 393 & 65.8 & 1.62 & 454 \\
\hline Canada & 64.8 & 0.40 & 15,653 & 74.1 & 0.47 & 2358 & 73.6 & 0.43 & 2047 \\
\hline Denmark & 64.1 & 0.53 & 5398 & 69.4 & 1.59 & 898 & 71.9 & 0.96 & 865 \\
\hline France & 59.3 & 0.48 & 5309 & 61.3 & 1.38 & 332 & 64.2 & 1.21 & 467 \\
\hline Germany & 56.7 & 0.51 & 5354 & 57.9 & 1.17 & 630 & 60.6 & 1.48 & 520 \\
\hline Great Britain & 65.6 & 0.37 & 12,331 & 70.5 & 1.02 & 753 & 72.2 & 0.92 & 1073 \\
\hline Greece & 66.8 & 0.62 & 4988 & 56.6 & 1.74 & 195 & 63.5 & 1.39 & 349 \\
\hline Ireland & 64.7 & 0.42 & 4949 & 71.4 & 1.01 & 395 & 70.7 & 1.03 & 397 \\
\hline Israel & 69.9 & 0.32 & 5470 & 67.8 & 1.05 & 481 & 69.8 & 0.97 & 647 \\
\hline Luxembourg & 63.0 & 0.42 & 2549 & 58.0 & 0.46 & 2101 & 68.6 & 0.9 & 649 \\
\hline Netherlands & 58.4 & 0.36 & 4785 & 64.7 & 1.42 & 292 & 66.7 & 1.53 & 308 \\
\hline New Zealand & 62.2 & 0.42 & 3306 & 69.8 & 0.93 & 509 & 69.5 & 0.93 & 705 \\
\hline Norway & 63.0 & 0.46 & 4766 & 69.7 & 1.21 & 383 & 66.3 & 1.24 & 307 \\
\hline Spain & 66.2 & 0.33 & 6029 & 66.8 & 1.21 & 371 & 69.0 & 1.24 & 336 \\
\hline Sweden & 59.7 & 0.50 & 4510 & 67.5 & 1.03 & 654 & 68.1 & 1.44 & 294 \\
\hline Switzerland & 58.5 & 0.60 & 4024 & 57.3 & 0.82 & 1117 & 60.6 & 1 & 719 \\
\hline United States & 67.2 & 0.37 & 4361 & 69.5 & 0.63 & 911 & 70.7 & 0.93 & 441 \\
\hline
\end{tabular}

PISA 2015. Means in bold are significantly different from means for non-migrant students at $p=0.05$, S.E. denotes standard error. Descriptive statistics for other PISA 2015 variables are in Additional file 1: Appendix S1 and their equivalents for 2006 are in Additional file 1: Appendix S2

contrary to our expectations (H1a), linguistic capital makes little difference in students' vocational ambitions. The strong version of H1a conjectured the linguistically diverse students to be determined to pursue higher status jobs, all else being equal.

\section{Linguistic capital not the key to occupational optimism}

The weak version of our first hypothesis (H1b) stipulated that bilingual immigrants will be most ambitious, with monolingual immigrants being less ambitious but still exceeding native students' expectations. It is considered in Fig. 2.

H1b finds support in Australia, Austria, Belgium, Canada, Ireland, Luxembourg, New Zealand, Norway and Switzerland, yet the differences between bilingual and monolingual students are minimal. Moreover, the data from Denmark, France, Germany, Great Britain, Greece, Israel, Netherlands, Spain, Sweden and the United States speak against H1b. Supplementary analyses of the PISA 2006 in Additional file 1: Appendix S2 reveal that linguistic capital differences tend to hold over time, in older and younger cohorts, except for Germany, Great Britain and Switzerland. Still, they tend to be very small in most countries, lending little empirical support to arguments about the link between linguistic capital and occupational optimism. Language differences matter little. Immigrants in most countries show more vocational optimism regardless of the spoken languages. This advantage transpires in both cohorts and all countries except Greece and Israel (Fig. 2 and Additional file 1: Appendix S2 Figure 1). 


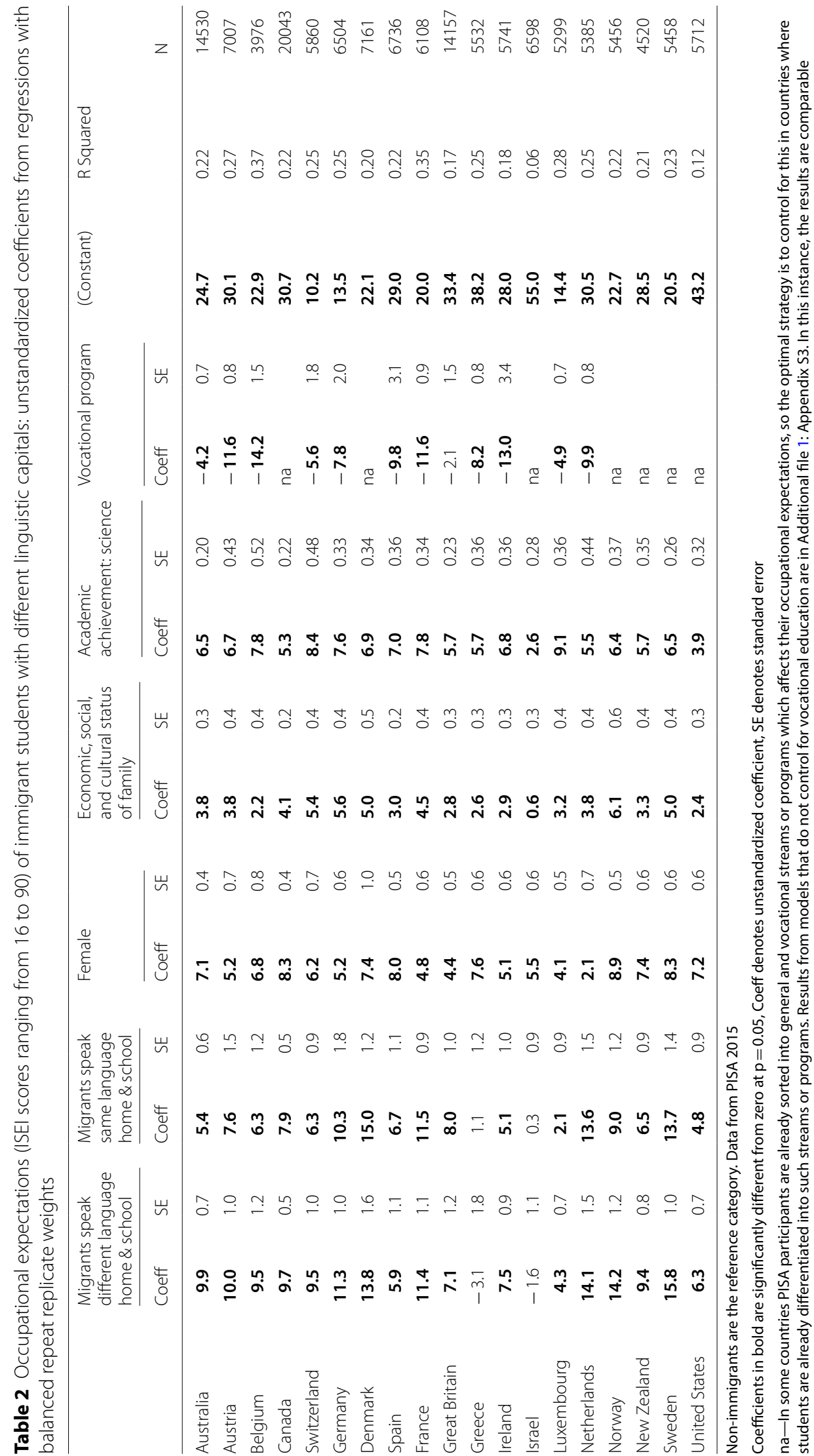




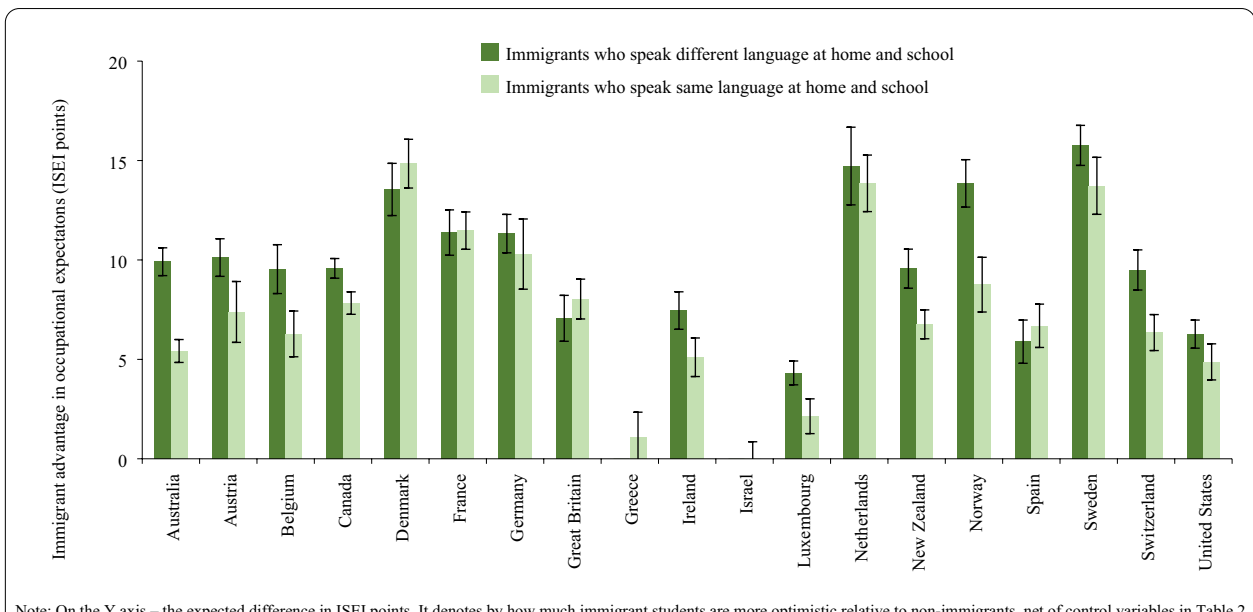

Fig. 2 Net gains (optimism) in occupational expectations (ISEI) of immigrants compared to non-immigrants, based on Table 2. Comparisons of gains over non-immigrants for (1) students who speak at home the same language as the language of PISA tests and (2) students who speak a different language at home. Unstandardized regression coefficients from Table 2. PISA 2015. On the Y axis-the expected difference in ISEI points. It denotes by how much immigrant students are more optimistic relative to non-immigrants, net of control variables in Table 2

\section{Orientation towards science employment as a strategic adaptation which contributes to the occupational optimism of immigrant youth}

PISA has no direct measures of either students or parents' perceptions that science is an equal playing field. Instead, we must rely on indirect evidence by demonstrating that immigrant students, regardless of their academic achievement, family background and conditions in host societies, accord science more instrumental value than other comparable students. Given the ideology of vocational choices reflecting personal preferences and self-realization rather than material gains or social approval, we also seek to establish whether immigrant students report significantly greater enjoyment of science than their schoolmates, net of their science performance. Although our earlier analyses distinguished between bilingual and monolingual youth, we found that the expected occupational status is broadly similar among immigrants with different language resources. Thus, to conserve space, we contrast, in the second part of the paper, just the immigrants and their non-immigrant peers. The analyses that include linguistic capital indicators are available upon request.

The estimates for the first part of our path analysis (Path A in Fig. 1b and c) are in Table 3. Immigrant students accord science higher instrumental value in 14 countries, with the average immigrant gain at roughly 0.19 of a standard deviation. Not in all countries do immigrant students orient themselves to science as a field essential for their future professional employment. In Germany, Ireland, Israel, Luxembourg, and Switzerland, there are no differences between these students and other adolescents, net of their gender, economic, cultural and social status, parental employment in science, vocational placement and prior science achievement. However, in other countries, immigrants value science as an area of study that leads to better employment prospects, which is consistent with the strategic adaptation argument. 


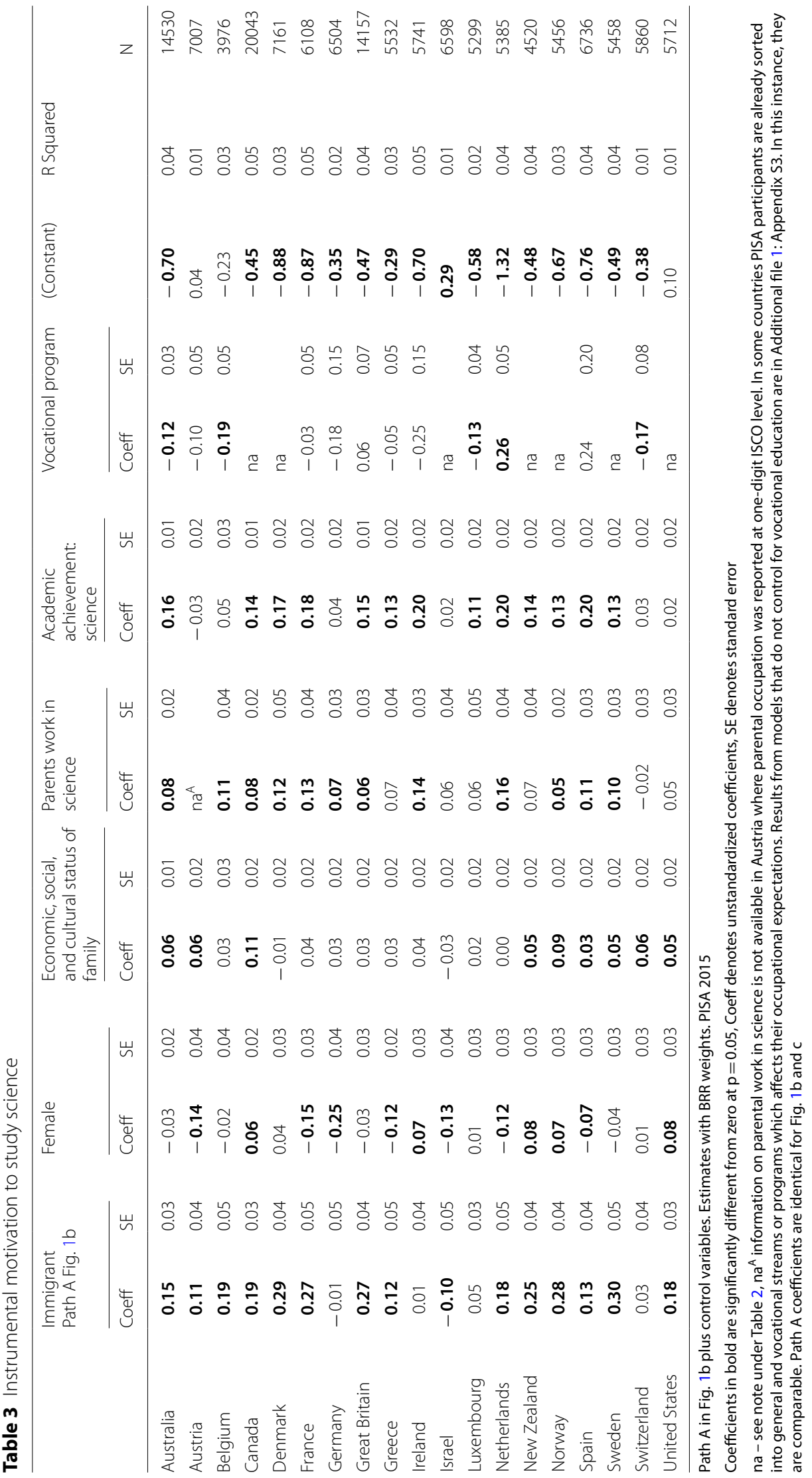


Moreover, immigrant students in all but one country (Israel) report enjoying science considerably more, by 0.29 of a standard deviation on average, than other students (Table 4). This effect also fits the argument that immigrants experience science as the learning field in which their efforts are purposeful and justly rewarded. Greater enjoyment of science does not prove that adolescents recognize and reflect on universalistic values associated with evaluating performance in school science. However, the nearly universal character of this effect suggests that it might originate from such features of school science that facilitate similar attitudes and experiences among diverse immigrants in varying contexts, rather than from the diversity of individual or school system characteristics.

As suggested by the strategic adaptation argument, this widespread enjoyment of science could spring from the shared implicit stereotype of science as a field governed by universalistic values with good vocational prospects and more merit-based assessment than other learning domains. This perception might enhance the satisfaction reported by immigrant students. They enjoy their science classes more, with the increment ranging from a tiny 0.10 of a standard deviation in Luxembourg to over half a standard deviation in Sweden. It is worth noting that immigrant enjoyment of science and instrumental valorisation of science is greater before we introduce controls for parental science employment in Table 5. This reduction in effect sizes indicates that some immigrant youths owe part of their positive orientations to science to their parents, who work as science professionals.

\section{Immigrants' positive orientation to science can explain some of their occupational optimism}

Table 5 reports the total, direct and indirect effects of immigrant status on occupational optimism and the direct impact of the instrumental approach to science and its enjoyment on the same dependent variable. The total effects are the effects of immigrant status before mediating variables are introduced into the path analysis in Fig. 1b. This analysis enables us to quantify the proportion of immigrant optimism attributable to these two mediating factors, as per our theory.

The theory finds no support in Germany, Israel, Greece, or the Netherlands, where migrant optimism either does not exist or cannot be attributed to science's favourable disposition. However, in 15 countries, appreciation of science accounts on average 6\%, of occupational optimism, which is comparable to the $8 \%$ reported by Feliciano and Lanuza as significant in their USA study (2016). That study assessed how schoolwork enjoyment boosted immigrant ambitions. Column 8 of Table 5 gives, in percentages, the share of the immigrant coefficients explained by the two mediating variables. It is possible that training for science professions might be less attractive to immigrants in those countries that offer better access to vocational training to place youth in non-professional science and technology employment, e.g. in Germany or the Netherlands (Tjaden and Hunkler 2017). However, elsewhere, between 2 and 12\% of occupational optimism can be explained by a favourable predisposition to science. These effects also appear in PISA 2006, where the effect ranges from 1 to $30 \%$ with the average $14 \%$ of high-status expectations attributable to immigrants' positive orientation towards science (Table 5, Column 9 and Additional file 1: Appendix S2, Table 10). The reduction in magnitude in the mediated effects from 14 to $6 \%$ between 2006 and 2015 suggests that, while strategic 


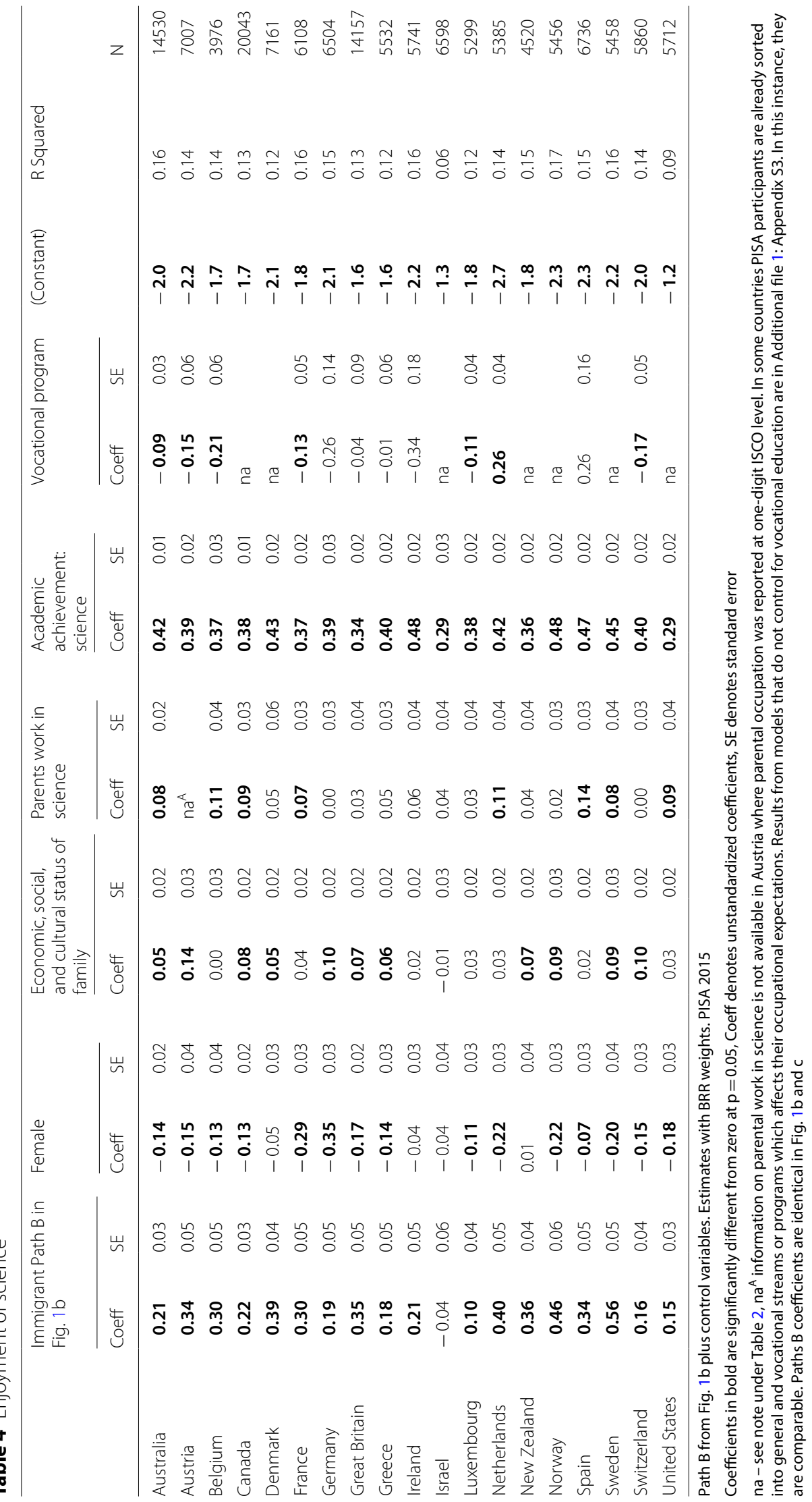




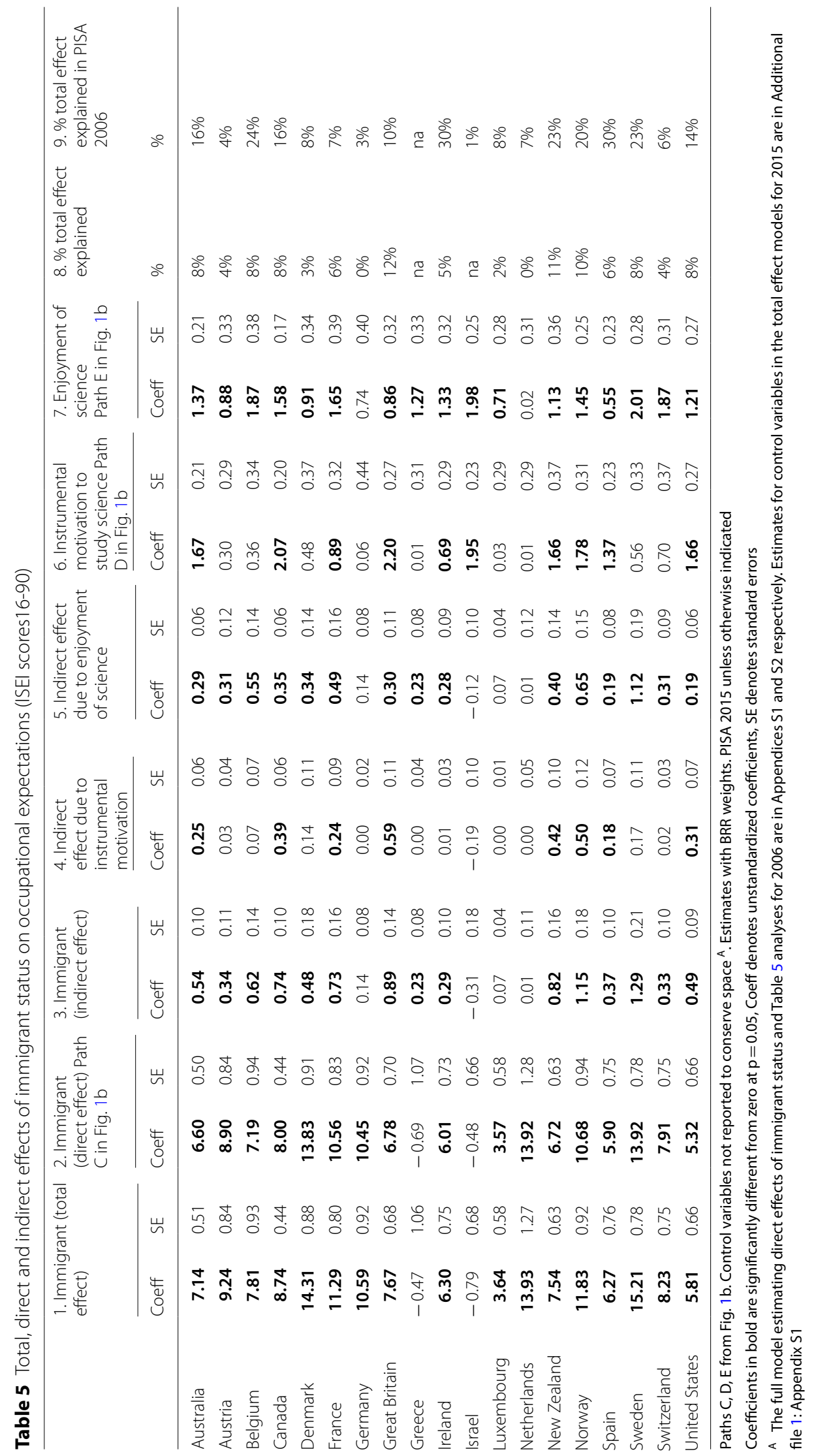


adaptation via orientation towards science is still detectable, it is an approach that has been slowly losing its appeal in the last decade.

\section{Immigrant students aim to enter high-status employment in science}

Finally, as the strategic adaptation argument predicts that more immigrants than their otherwise comparable peers will desire to enter science professions, Table 6 replicates the path analysis from Table 5, using the plan to work in a science profession as the dependent variable. Immigrant students are indeed more interested in science careers (OECD 2016b). Still, it is not clear to what extent the instrumental value of science and its enjoyment could account for immigrants' greater interest.

Table 6 results closely correspond to the patterns in Table 5. Only immigrants in Greece and Israel do not show more interest in science professions than other students. Everywhere else, immigrants tend to opt for science careers. In Additional file 1: Appendix S4, we replicate our path analysis on standardized coefficients for readers who wish to compare coefficients for different variables. Here, however, we present unstandardized estimates which are more meaningful, particularly for binary indicators such as immigrant status. Overall, in most countries, students' plans to work in science can be partly, from 5 to $41 \%$, explained by the combined influence of enjoyment of science and its perceived instrumental value. Germany is the only country where immigrants are more interested in science for reasons other than those considered here. Thus, the strategic adaptation argument holds promise in most countries considered here if we allow for universalistic values prevailing in science education and employment, and their appeal to young immigrants. These analyses provide tentative rather than ultimate support for the theories that inform them. Without direct measures of perceived universalism in science and the role of potential discrimination, we cannot eliminate other possible explanations for these patterns. However, the theory that inspired our analysis is an excellent candidate to account for the regularities in Tables 5 and 6. Science careers are mostly high-status occupations (Xie and Goyette 2003). Additional file 1: Appendix S1 shows that in each of these countries, the plan of entering a science occupation is associated with about 20 extra ISEI extra points of occupational ambition. A similar pattern transpires in the PISA 2006 data (Additional file 1: Appendix S2), with the share of explained variance in both dependent variables being even higher in most countries a decade earlier.

\section{Discussion and conclusion}

According to Yosso's (2005) version of the critical race theory, immigrant adolescents who speak different languages at home and school have unique linguistic capital and are more occupationally ambitious than their peers. However, we have found that immigrants who speak the same language at home and school are, in many of 19 countries considered here, equally ambitious.

In light of this analysis, linking occupational optimism to linguistic capital is not fruitful; however, the strategic adaptation argument is more promising. This theory posits that science is seen as an equal playing field for immigrants whose cultural competencies and social capital make them less enthusiastic about entering creative arts, politics, or other humanistic areas of study. The preference for science has been shown to raise the 


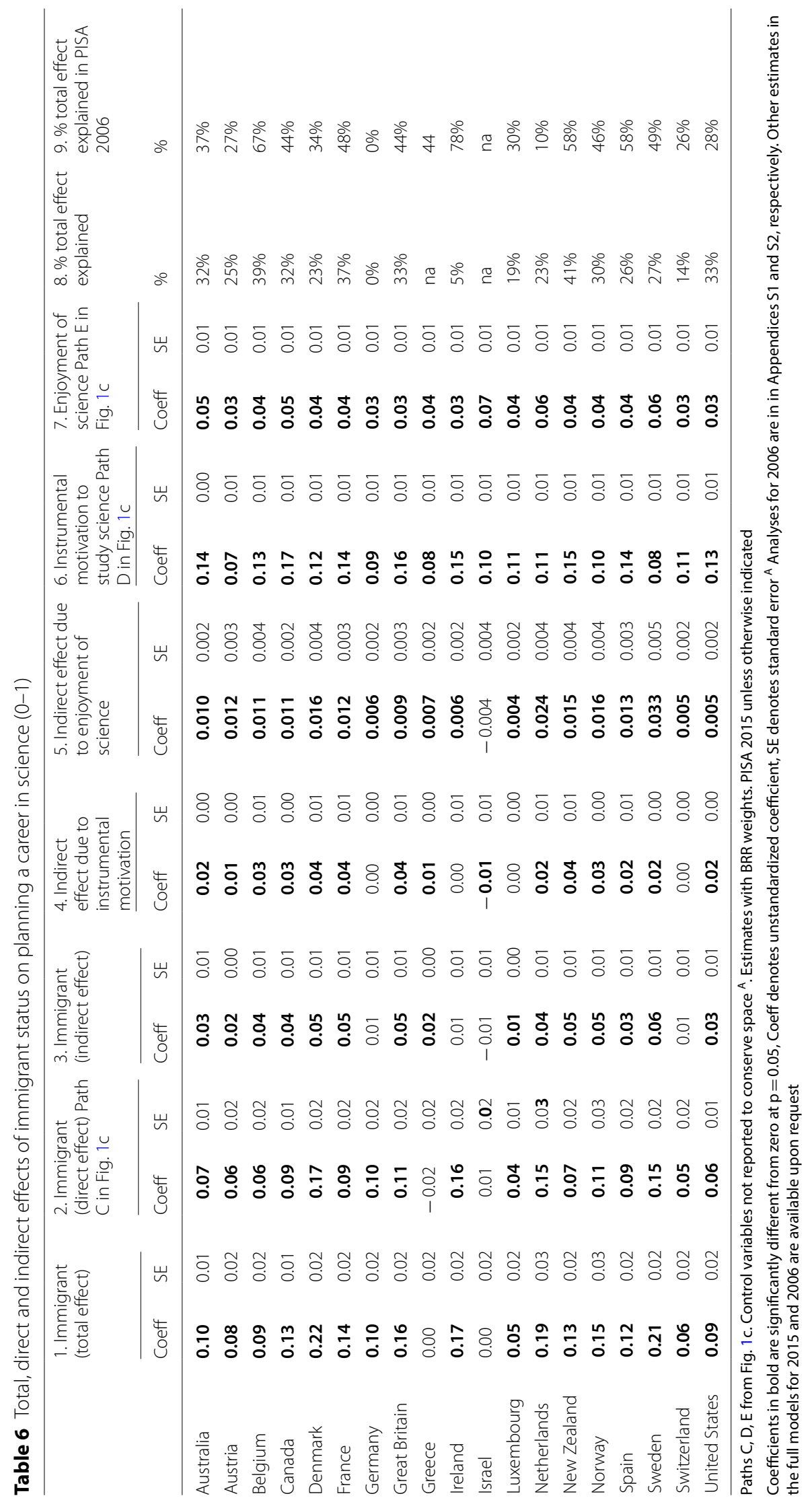


occupational optimism of many young immigrants, but it does not account for it all. In our sample of 19 countries, immigrants in Israel and Greece are no more ambitious than their peers. Still, these countries are exceptions in a more typical pattern of high occupational expectations of young migrants. It is possible that the bilingual capital hypothesis could be more useful if it were extended to all students. Future interrogations of the PISA data will hopefully shed more light on this issue.

We find that instrumental orientation towards science and enjoyment of science are higher among immigrant youth. They account for up to $12 \%$ of their occupational optimism expressed by the expected status of their future occupation in 2015 and up to 30\% in the 2006 data. This effect transpires because immigrant youth are more likely to plan to become medical doctors, engineers, information technology professionals and other science professionals. A positive orientation towards science accounts for up to $41 \%$ of the inclination to plan a science career in the 2015 cohort and up to $68 \%$ in the 2006 cohort.

Our analyses rely on cross-sectional data and are correlational. Thus, we cannot prove that migrants opt for science specialization as a pathway to high-status employment because they see it as a strategy to circumvent potential discrimination. Still, the data suggest that this line of argument deserves serious consideration in future studies that will include direct measures of immigrant perceptions of science as an equal playing field. They ought to probe into reasons for greater enjoyment of science reported by immigrants and compare science assessment practices to assessment in other academic domains at school. Another promising line of inquiry would be to examine the extent to which migrant students are ambitious because they want to maintain their parents' country-of-origin occupational status which may be higher than the status attached to their occupations in host countries. While we controlled for parental education, which is less likely to change post-migration, we had no data on parental occupations of migrant parents in their countries of origin. It is possible that occupational status of migrant parents tends to be lower in host countries compared to what they enjoyed in their homes of origin and their children model their expectations on the original status. If this is the case, migrant adolescent might not be as ambitious as they seem to be, when this is not taken into account. Moreover, we do not have longitudinal data to better model what affects the variation in occupational expectations at later stages when the disparities between migrants and non-migrants might diminish or widen. Notably, our samples of immigrants are relatively small (see Table 1). Finally, as PISA is administered only to students fluent in the language of the PISA tests, its migrant samples are likely not to represent entire immigrant youth populations in these countries. The patterns of immigrant optimism that our correlational study suggests are neither universal nor are immigrant status effects identical across countries and cohorts. Undoubtedly, this reflects the variation in immigrant group compositions, countries of origin, host country contexts, and many other factors highlighted in previous single-country studies. Above and beyond this variation, however, we have found broad similarities in the vocational orientations of diverse immigrant youth in two different cohorts of 16 year-olds who came of age in 2006 and 2015.

Therefore, we propose that this analysis constitutes sufficient grounds for more discussion and research into those universal triggers of occupational optimism among 
adolescent immigrants with diverse social and personal characteristics. They appear to be shared across many host societies. With the progression of cultural, economic, and educational globalization, it is worthwhile to complement the study of heterogeneity in the interactions between cultural and country-specific contexts that affect immigrant motivation with accounts of the impact of globally shared attainment ideologies that maintain their influence over time. Our results suggest that if implicit stereotypes of science as a more merit-based achievement field exist, they could be embraced by many immigrant families. However, this acknowledgment does not deny the considerable variation in the sizes of in effects we found across countries. Moreover, we saw a decrease in the popularity of this apparent adaptation strategy between 2006 and 2015. Notwithstanding that, opting for science careers as a pathway into high status employment among migrants appears to underpin vocational optimism among many immigrants in older and younger cohorts of adolescents across the OECD.

\section{Supplementary Information}

The online version contains supplementary material available at https://doi.org/10.1186/s40536-021-00101-9.

Additional file 1. Additional tables.

Acknowledgements

The authors thank Zsuzsa Blaskó of the European Commission - Joint Research Centre for helpful comments.

Authors' contributions

Conceived and designed the analysis: Sikora 75\%, Pokropek 25\%. Performed the analysis: Sikora 50\%, Pokropek 50\%. Wrote the paper: Sikora 75\%, Pokropek 25\%. Both authors read and approved the final manuscript.

Funding

The authors received no financial support for the research, authorship, or publication of this article.

Availability of data and materials

The data used in this paper are publicly available.

\section{Declarations}

Competing interests

The Authors declare that there is no conflict of interest.

Author details

${ }^{1}$ Research School of Social Sciences, Australian National University, Canberra, ACT 2601, Australia. ${ }^{2}$ Polish Academy of Sciences, Warsaw, Poland.

Received: 14 October 2020 Accepted: 7 April 2021

Published online: 27 April 2021

References

Alarcon, A., Parella, S., \& Yiu, J. (2014). Educational and occupational ambitions among the Spanish' second generation': The case of Barcelona. Journal of Ethnic and Migration Studies, 40(10), 1614-1636. https://doi.org/10.1080/1369183x. 2013.831550.

Avvisati, F., \& Keslair, F. (2017). REPEST: Stata module to run estimations with weighted replicate samples and plausible values. Statistical Software Components.

Blasko, Z., Pokropek, A., \& Sikora, J. (2018). Science career plans of adolescents: patterns, trends and gender divides. Retrieved from http://publications.jrc.ec.europa.eu/repository/bitstream/JRC109135/jrc109135_crell_tr_science_career_plans. pdf doi:https://doi.org/10.2760/251627

Bourdieu, P. (1984). Distinction: A social critique of the judgment of taste. Harvard University Press.

Bourdieu, P., \& Passeron, J.C. (1990). Reproduction in education, society and culture. (Vol. 4). New York: Sage.

Boyd, M., \&Tian, S. (2018). Is STEM Education Portable? Country of education and the economic integration of STEM

immigrants. Journal of International Migration and Integration, 1, 1-39. 
Cebolla-Boado, H., \& Martinez De Lizarrondo, A. (2015). The educational expectations of immigrants in Navarra. Immigrant optimism or school effects? Revista Internacional de Sociologia, 73(1), 1-13. https://doi.org/10.3989/ris.2013.02. 22.

Cebolla-Boado, H., \& Soysal, Y. N. (2018). Educational optimism in China: Migrant selectivity or migration experience? Journal of Ethnic and Migration Studies, 44(13), 2107-2126. https://doi.org/10.1080/1369183X.2017.1417825.

Charles, M., \& Bradley, K. (2009). Indulging our gendered selves? Sex segregation by field of study in 44 countries. American Journal of Sociology, 114(4), 924-976.

Chiswick, B. R., \& Taengnoi, S. (2007). Occupational choice of high skilled immigrants in the United States. International Migration, 45(5), 3-34.

Clarkson, P. C. (2007). Australian Vietnamese students learning mathematics: High ability bilinguals and their use of their languages. Educational Studies in Mathematics, 64(2), 191-215.

Davis, A. (2013). Pediatrician or professional athlete? Gender, ethnicity, and occupational aspirations of urban adolescents. Journal of Education for Students Placed at Risk, 18(2), 141-152. https://doi.org/10.1080/10824669.2013.797883.

Devine, D. (2009). Mobilizing capitals? Migrant children's negotiation of their everyday lives in school. British Journal of Sociology of Education, 30(5), 521-535. https://doi.org/10.1080/01425690903101023.

Dronkers, J., Van Der Velden, R., \& Dunne, A. (2012). Why are migrant students better off in certain types of educational systems or schools than in others? European Educational Research Journal, 11(1), 11-44.

Dustmann, C., Frattini, T., \& Lanzara, G. (2012). Educational achievement of second-generation immigrants: An international comparison. Economic Policy, 27(69), 143-185.

Entorf, H., \& Minoiu, N. (2005). What a difference immigration policy makes: A comparison of PISA scores in Europe and traditional countries of immigration. German Economic Review, 6(3), 355-376. https://doi.org/10.1111/j.1468-0475. 2005.00137.x.

Feliciano, C., \& Lanuza, Y. R. (2016). The imigrant advantage in adolescent educational expectations. International migration review, 50(3), 758-792. https://doi.org/10.1111/imre.12183.

Feliciano, C., \& Rumbaut, R. G. (2005). Gendered paths: Educational and occupational expectations and outcomes among adult children of immigrants. Ethnic and Racial Studies, 28(6), 1087-1118. https://doi.org/10.1080/014198705002244 06.

Ganzeboom, H. B. G., de Graaf, P. M., \& Treiman, D. J. (1992). A standard international socio-economic index of occupational status. Social Science Research, 21, 1-56. https://doi.org/10.1016/0049-089X(92)90017-B.

Ganzeboom, H. B. G., \& Treiman, D. J. (2010). Occupational status measures for the new international standard classification of occupations ISCO-08; with a discussion of the new classification. Retrieved from http://www.harryganze boom.nl/isol/isol2010c2-ganzeboom.pdf

Gil-Hernández, C. J., \& Gracia, P. (2018). Adolescents' educational aspirations and ethnic background: The case of students of African and Latin American migrant origins in Spain. Demographic Research, 38(1), 577-618. https://doi.org/10. 4054/DemRes.2018.38.23.

Hakuta, K. (2010). Bilingualism. In L. R. Squire (Ed.), Encyclopedia of Neuroscience. (pp. 173-178). New York: Elsevier Ltd.

Haller, A. O., \& Portes, A. (1973). Status attainment processes. Sociology of education, 1, 51-91.

Han, S. (2016). Staying in STEM or changing course: Do natives and immigrants pursue the path of least resistance? Social Science Research, 58, 165-183. https://doi.org/10.1016/j.ssresearch.2015.12.003.

Hillmert, S. (2013). Links between immigration and social inequality in education: A comparison among five European countries. Research in Social Stratification and Mobility, 32, 7-23. https://doi.org/10.1016/j.rssm.2013.02.002.

ILO. (2012). International Standard Classification of Occupation: ISCO-08: Volume 1: Structure, group definitions and correspondence tables. Geneva: International Labour Office (ILO).

Inglehart, R., \& Welzel, C. (2005). Modernization, cultural change, and democracy: The human development sequence. . Cambridge: Cambridge University Press.

Kao, G., \&Tienda, M. (1995). Optimism and achievement: The educational performance of immigrant youth. Social Science Quarterly, 76(1), 1-19.

Kasinitz, P., Mollenkopf, J. H., Waters, M. C., \& Holdaway, J. (2008). Inheriting the City: The Children of Immigrants Come of Age. . Russell Sage Foundation.

Khattab, N. (2018). Ethnicity and higher education: The role of aspirations, expectations and beliefs in overcoming disadvantage. Ethnicities, 18(4), 457-470. https://doi.org/10.1177/1468796818777545.

Lee, J., \& Zhou, M. (2015). The Asian American Achievement Paradox. . Russell: Sage Foundation.

Little, R. J. A., \& Rubin, D. B. (2002). Statistical analysis with missing data. (2nd ed.). Wiley.

Medvedeva, M., \& Portes, A. (2017). Immigrant bilingualism in Spain: An asset or a liability? International Migration Review, 51(3), 632-666. https://doi.org/10.1111/imre.12243.

Min, P. G., \& Jang, S. H. (2015). The concentration of Asian Americans in STEM and health-care occupations: An intergenerational comparison. Ethnic and Racial Studies, 38(6), 841-859. https://doi.org/10.1080/01419870.2014.941891.

Newman, D. A. (2014). Missing data: Five practical guidelines. Organizational Research Methods, 17(4), 372-411. https:// doi.org/10.1177/1094428114548590.

OECD. (2007). PISA 2006 Technical Report. Organization for Economic Co-operation and Development.

OECD. (2016a). Getting skills right: Assessing and anticipating changing skill needs. OECD Publishing.

OECD. (2016b). PISA 2015 Results: Excellence and Equity In Education. (Vol. I). OECD Publishing.

OECD. (2017). PISA 2015 Technical Report. OECD Publishing.

Ogbu, J. (1978). Minority education and caste: The American system in cross-cultural comparison. . New York: Academic Press.

Portes, A., \& MacLeod, D. (1999). Educating the second generation: Determinants of academic achievement among children of immigrants in the United States. Journal of Ethnic and Migration Studies, 25(3), 373-396.

Portes, A., \& Rumbaut, R. G. (2001). Legacies: The story of the immigrant second generation. California: Univ of California Press.

Portes, A., \& Rumbaut, R. G. (2006). Immigrant America: a portrait. (3rd ed.). University of California Press.

Portes, A., \& Rumbaut, R. (2014). Immigrant America: A portrait revised, updated, and expanded, Berkeley and Los Angeles. .

California: University of California Press. 
Rumbaut, Rubén G., Generation 1.5, Educational Experiences of (2012). James A. Banks, ed., Encyclopedia of Diversity in Education, Sage Publications, 2012, SSRN: https://ssrn.com/abstract=2182167

Schafer, J. L., \& Graham, J. W. (2002). Missing data: our view of the state of the art. Psychological Methods, 7(2), 147.

Schleicher, A. (2015). Helping immigrant students to succeed at school-and beyond. OECD.

Sikora, J., \& Pokropek, A. (2012a). Gender segregation of adolescent science career plans in 50 countries. Science Education, 96(2), 234-264.

Sikora, J., \& Pokropek, A. (2012b). Intergenerational transfers of preferences for science careers in comparative perspective. International Journal of Science Education, 34(16), 2501-2527. https://doi.org/10.1080/09500693.2012.698028.

Suárez-Orozco, M. M. (2018). Children of immigration. Paper presented at The 4th Policy Forum of the Strength through Diversity project New Brunswick, Canada. http://www.oecd.org/education/school/Children-of\%20-Immigration.pdf

Swidler, A. (1986). Culture in action - symbols and strategies. American Sociological Review, 51(2), 273-286.

Tjaden, J. D., \& Hunkler, C. (2017). The optimism trap: Migrants' educational choices in stratified education systems. Social Science Research, 67, 213-228. https://doi.org/10.1016/j.ssresearch.2017.04.004.

Tseng, V. (2006). Unpacking immigration in youths'academic and occupational pathways. Child Development, 77(5), 1434-1445. https://doi.org/10.1111/j.1467-8624.2006.00946.x.

Weenink, D. (2008). Cosmopolitanism as a form of capital: Parents preparing their children for a globalizing world. Sociology, 42(6), 1089-1106.

Wicht, A. (2016). Occupational aspirations and ethnic school segregation: Social contagion effects among native German and immigrant youths. Journal of Ethnic and Migration Studies, 42(11), 1825-1845. https://doi.org/10.1080/1369183X. 2016.1149455

Xie, Y., \& Goyette, K. (2003). Social mobility and the educational choices of Asian Americans. Social Science Research, 32(3), 467-498. https://doi.org/10.1016/S0049-089X(03)00018-8.

Yiu, J. (2013). Calibrated ambitions: low educational ambition as a form of strategic adaptation among Chinese youth in Spain. International Migration Review, 47(3), 573-611.

Yosso, T. J. (2005). Whose culture has capital? A critical race theory discussion of community cultural wealth. Race, Ethnicity and Education, 8(1), 69-91.

\section{Publisher's Note}

Springer Nature remains neutral with regard to jurisdictional claims in published maps and institutional affiliations.

\section{Submit your manuscript to a SpringerOpen ${ }^{\odot}$ journal and benefit from:}

- Convenient online submission

Rigorous peer review

- Open access: articles freely available online

- High visibility within the field

- Retaining the copyright to your article

Submit your next manuscript at $\boldsymbol{\Delta}$ springeropen.com 